\title{
My curry story and cultural additivity
}

\author{
Tam-Tri Le \\ Centre for Interdisciplinary Social Research \\ Phenikaa University, Hanoi, Vietnam \\ Written in Ho Chi Minh city, on June 1'st, 2021 \\ OSF Preprints, DOI: 10.31219/osf.io/pg3rn
}

Cuisine is a major part of human culture, and I believe food can talk to oneself about cultural values on a very personal level. When I first heard about the concept of cultural additivity [1], one of the things I could immediately relate to was my experience with curry.

When I was a kid, my mother sometimes made curry. She used Indian-style curry powder, chicken, sweet potato, coconut milk, and other spices. It is a common recipe for Vietnamese curry, and the soup has an orange-reddish color with strong, distinct fragrance. We eat it with bread or rice, both quite delicious. That was the only style I knew for the concept of curry at the time.

Starting my university years, I went to Japan and got to experience Japanese curry. At first it feels weird. The soup is very thick with sepia color, and the scent and taste are different from what I was used to. Curry was introduced to Japan by the British, so it shares some similarities with other European sauces. But the Japanese have their own ways of enjoying curry. They often make it with curry roux, beef, potato, and carrot. Curry was eaten with rice, noodles, or as soft curry-bread. Different from what I had thought, curry dishes are extremely popular in Japan.

I have some friends in Japan who have been in India and know how to make Indian curry with original spices. Depending on the regional recipe, the curry can be very strong or very mild, which again changed my perception about curry. I also went to a Nepalese restaurant that serves South-Asian-style curry dishes in Japan. The curry there actually feels like a mixture of various styles, still it turns into quite an attractive and unique taste.

Speaking about mixing things up, I myself tried many different ways to prepare some fresh curry dishes in my own favorite styles. I have used squid, clam, fish, egg, bacon, grilled steak, and all kinds of root vegetables. I also tried mixing curry in making fried rice or deep-fried meat dishes. Probably it can be said that these are curry with added personal cultural values, or the other way - my personal cuisine with added curry values.

As a researcher, I do not only look at this as fascinating experiences, but also in terms of a framework for such phenomena - cultural additivity [1]. Besides, the interactions and 
changes of values both in various cultures and in my mindset (e.g. the concept of curry) should also be examined with a systematic approach, such as by using the Mindsponge framework [2,3]. Regarding the current situation of Vietnam's social sciences and humanities [4], it is true that a proactive attitude is necessary, especially in the young generations of scientists [5]. And I believe that personal experiences are the treasure trove hidden right inside each researcher.

\section{References}

1. Vuong, Q. H., et al. (2018). Cultural additivity: Behavioural insights from the interaction of Confucianism, Buddhism and Taoism in folktales. Palgrave Communications, 4, 143. https://doi.org/10.1057/s41599-018-0189-2

2. Vuong, Q. H. (2016). Global Mindset as the Integration of Emerging SocioCultural Values Through Mindsponge Processes: A Transition Economy Perspective. In J. Kuada (Ed.), Global Mindsets: Exploration and Perspectives (pp. 109-126). Routledge. https://doi.org/10.4324/9781315736396-8

3. Vuong, Q. H., \& Napier, N. K. (2015). Acculturation and global mindsponge: An emerging market perspective. International Journal of Intercultural Relations, 49, 354-367. https://doi.org/10.1016/j.ijintrel.2015.06.003

4. Vuong, Q. H., et al. (2018). An open database of productivity in Vietnam's social sciences and humanities for public use. Scientific Data, 5, 180188. https://doi.org/10.1038/sdata.2018.188

5. Vuong, Q.-H. (2019). Breaking barriers in publishing demands a proactive attitude. Nature Human Behaviour, 3, 1034. https://doi.org/10.1038/s41562-0190667-6 